\title{
FORMATION OF FUTURE PHILOLOGISTS' PROFESSIONAL COMPETENCE IN THE ASPECT OF AXIOLOGICAL APPROACH
}

\author{
Danylyuk Serhiy ${ }^{1}$ a * \\ ${ }^{1}$ Scientific-Research Institute of Pedagogical Education, Social Work and Arts, \\ Bohdan Khmelnytsky National University at Cherkasy, Ukraine \\ asedan@bigmir.net
}

\begin{abstract}
Keywords: future philologists, professional training, professional competence, axiological approach, theory of education.
\end{abstract}

\begin{abstract}
The formation of future philologists' professional competence in the aspect of axiological approach is studied in the paper. Taking into account axiological ideas, a set of culturaland-humanistic educational functions are identified. Among them there are: development of spiritual strength, abilities and skills that enable a person to overcome life's obstacles; formation of character and moral responsibility; providing opportunities for personal and professional selfrealization; mastering the means that are necessary to achieve intellectual and moral freedom; creating conditions for creative and spiritual growth of an individual. As far as humanistic aim of education is concerned, a number of problems is outlined. Among them there are: awareness of the intrinsic value of an individual as a carrier of high humanistic principles, its unique individuality and creative nature; recognition of the harmonious development of a personality as goal and the main purpose of a man; understanding of creative nature of activity, awareness of the need of spiritual costs and self-improvement for its implementation; development of humanitarian culture as a set of personality traits - the unity of the internal moral essence and external behavioral expression, subtle perception of beauty and ugliness in human relationships, empathy, sensitivity, expressiveness, optimism, kindness. Several approaches to the classification of educational values were suggested. Among them there are horizontal plane of existence of pedagogical values (valuesgoals, values-means, values-knowledge, values-relationships and values-qualities) and vertical plane of existence of pedagogical values (social-and-educational, vocational-and-group and individualand-personal values), emphasizing the syncretic nature of these values.
\end{abstract}

\section{INTRODUCTION}

From the beginning of the 90s of the 2oth century Ukrainian society is in conditions of transition from one socio-economic system to another one. This transition is closely associated with the change of lifestyle of Ukrainians, overestimation of their established norms and values, including norms and values in the educational system. Educational reform in Ukraine provides conditions for personal development and creative self-realization of every citizen. This will increase the nation's intellectual potential, comprehensive personality development as the highest value of society. Currently, the main pedagogical idea of modernity is life-long education. Its implementation requires considerable attention to overall development of an individual, his autonomy in decision-making and cognitive activity.

At the present stage of higher education, the goal is to bring up competent professionals while their studying at universities. These competent professionals should be able to solve a variety of professional tasks. In our case, we mean the need of formation of future philologists' professional competence. This competence is formed by using a variety of approaches in the educational process. 


\section{ANALYSIS OF PUBLICATIONS}

One of these approaches is axiological approach. It's necessary to mention that in contemporary higher education it is given great importance. Thus, the appeal to this approach is widely seen in Humanities (E. Bondarevskaya, I. Isayev, A. Kyr'yakova, M. Nykandrov, N. Rozov, V. Slastyonin, L. Stepashko, N. Shchurkova). Relevance of researches in pedagogical axiology is caused by the need to modernize education and develop new strategies of its development.

\section{THE AIM OF THE INVESTIGATION}

The aim of the paper is a task to highlight features of formation of future philologists' professional competence in terms of axiological approach.

\section{RESULTS}

The new millennium was a kind of turning point for humanity, many spiritual moral values, which over last years have shaped the harmonization of life and work of people, the whole system of human relationships with the world, were lost [1, p. 52]. V. Ilyin speaks of "lack of humanity" and lack of "tradition of mercy, compassion , responsibility before the future" [2, p. 164], which makes people reflect about the trajectory of further movement of humanity.

The society, which formed a spiritual vacuum in which there is no clear system of values, can not form a strong nation. Education, which is not inherent of core values is powerless before spiritual and moral crisis. It should be based on axiological approach, a priority of which aims at developing future professional's value outlook, formation of his moral-and-spiritual form [3, p. 20].

In this connection, one of the major problems of modern pedagogy is identification of humanistic potential and development of conceptual foundations of spiritual-and-moral education. According to Yu. Passov, only homo moralis - a moral, spiritual person can be considered the aim of education, because education is in fact becoming a person [4, p. 54-55].

Humanization of education suggests creating a system which could provide "... the unity of a person's continuous general cultural, social-and-moral and professional development ..." [5, p. 444].

Despite of the education reform which takes place in the whole world and in our country, analysis of changes shows that modern institute of education is not fully consistent with the principle of humanization of social life, and symbiosis of getting high professional training and spiritual development of a person in higher school is a major, but still elusive purpose [3, p. 21].

B. Gershunsky sees the reason of the lack of implementation of humanistic educational reforms in the fact that "... any transformations, reforms and innovations as soon as they claim to successful implementation and real support in education should begin with a system that is ahead of these reforms and innovations of pedagogical education, with future teachers' training, and in especially extreme and urgent situations - with retraining of existing teachers"[6, p. 128].

To make education really become truly humanistic and contribute to the formation of future philologists as professionals of new time who possess not only high professional competence, but also formed system of value orientations and wide moral worldview, there is a grounded necessity to change the strategy of higher education. First of all, emphasis must be placed on future philologists' professional training. The main focus is also on the formation and development of future philologists' value orientations. Axiology and axiological approach to education play a special and very important role. The use of axiological approach within the study of pedagogical disciplines is considered to be grounded. This will add a special, value orientation of the process of future philologists' professional training [3, p. 21]. Consistent and competent implementation of acmeological approach in the educational system enables to promote "the development of human nature, multifaceted human relations, complex dialectics of the soul ..." [1].

Axiological approach inherent in such Humanities as Philosophy, Psychology, Pedagogy, Aesthetics, Ethics, Sociology, Cultural Studies. However, of particular interest is the synthesis of 
values and philological education, opportunities and methods of implementation of axiological approach in future philologists' training.

Interest of axiologization of philological education is caused by the need to use axiological approach in today's educational environment, which should be aimed at building "a man who, in his turn, should be based on a renewed philosophical picture of the world, human values" [7, p. 13].

To examine the basic principles of the axiological approach to philological education one should apply directly to the concepts of "axiology " and "axiological approach".

Axiology (from Greek axio - value, logos - word ) is a philosophical discipline which examines the category of "value", characteristics, structure and hierarchy of values in the world, ways of its knowing and its ontological status, nature and specificity of value judgments [8, p. 22].

The category of "value" is the basis of axiological approach. Axiological approach is an approach to education that has value base. It is based on common values and self-worth of an individual. Underlying acmeological The humane conception of interactional world, according to which our world is a world of a whole man, and a man is the highest value of society, is in the basis of axiological approach [3, p. 34-35].

In pedagogy the axiological approach is an essential component that allows us to consider education as a socio- pedagogical phenomenon, which is reflected in its basic ideas: ofuniversal and fundamental character of human values, unity of aims and means, priority of the idea of liberty $[5, p$. 439].

Taking into account axiological ideas, V. Slastyonin identifies such cultural-and-humanistic educational functions [5, p. 238]:

1) development of spiritual strength, abilities and skills that enable a person to overcome life's obstacles;

2) formation of character and moral responsibility;

3) providing opportunities for personal and professional self-realization;

4) mastering the means that are necessary to achieve intellectual and moral freedom;

5) creating conditions for creative and spiritual growth of an individual.

Humanistic aim of education is harmonious development of a personality, and realization of this goal requires solving such problems, as [5, p. 441-442]:

1) awareness of the intrinsic value of an individual as a carrier of high humanistic principles, its unique individuality and creative nature;

2) recognition of the harmonious development of a personality as goal and the main purpose of a man;

3) understanding of creative nature of activity, awareness of the need of spiritual costs and self-improvement for its implementation;

4) development of humanitarian culture as a set of personality traits - the unity of the internal moral essence and external behavioral expression, subtle perception of beauty and ugliness in human relationships, empathy, sensitivity, expressiveness, optimism, kindness.

Profession of a philologist itself has a humanistic nature, because humanistic values act as "eternal benchmarks", which are guided by future philologists in the exercise of their professional activities. In the process of formation of future philologists' professional competence there are also their professional pedagogical values $[5$, p. 36]. They are norms that regulate professional activities and act as informative-and-efficient system that serves as indirect link between the formed social ideology in education and future philologists' activities [5, p. 33].

There are several approaches to the classification of educational values. So, I. Isayev singles horizontal plane of existence of pedagogical values (values-goals, values-means, values-knowledge, values-relationships and values-qualities) and vertical plane of existence of pedagogical values (social-and-educational, vocational-and-group and individual-and-personal values), emphasizing the syncretic nature of these values [9, p. 64-65]. 
Social-and-educational values reflect the nature and content of the values that operate in different social systems, manifesting itself in public consciousness. They are a set of ideas, perceptions, norms, rules and traditions that govern the activities of society in education.

Professional-and-group values can be represented in the form of ideas, concepts, rules governing and directing future philologists' professional activities within certain educational institutions. The set of such values is holistic in nature, it has relative stability and repeatability.

Individual-and-personal values act as a social-and-psychological formation, which reflects goals, motivations, values, guidelines and other ideological personality characteristics that are taken together as a system of value orientations.

Values-goals act as a dominant axiological function in the system of other professional values, as in objectives basic content of future philologists' activities is reflected.

Values-means are three interdependent subsystems: 1) proper professional actions aimed at resolving the vocational-and-educational and individual-and-developmental tasks (training and educational technologies); 2) communication actions that can realize personally and professionally oriented tasks (communication technologies); 3) actions that reflect future philologists' subjective nature. This kind of actions is integrative in nature, as it combines all the three subsystems into a single axiological function. Values-means are divided into such groups, as values-relationships, values-qualities and values-knowledge.

Values-relations provide future philologists with reasonable and adequate construction of educational process and interaction with its subjects.

In the hierarchy of educational values the highest rank have values-qualities, because they manifest themselves as future philologists' individual-and-professional characteristics [5, p. 91].

There is such division of pedagogical values [5, p. 38]:

1) values associated with the self-assertion by a personality of its role in social and professional environment (social significance of a pedagogist's work, prestige of educational activities, recognition of the profession by the closest personal environment, etc.);

2) values that satisfy the need for communication and expand its range (communication with students, colleagues, reference people, experiencing students' love and affection, exchange of spiritual values, etc.);

3) values that are oriented at self-development of creative personality (the possibility of development of professional-and-creative abilities, involvement to the world culture, classes in favorite subject, continuous self-improvement, etc.);

4) values that enable self-actualization (creative character of a teacher's work, romance and excitement of teaching profession, ability to help socially disadvantaged children, etc.);

5) values that enable satisfaction of pragmatic needs (getting a guaranteed civil service, salary and duration of a holiday, record growth, etc.).

It should be noted that all the above listed educational values are not necessarily available in the system of values of all future philologists. This is connected not only with future philologists' individual personal characteristics, but with objective external laws, which largely determine the status of a teacher's profession in society. However, every future philologist has a system of professional educational values he considers to be crucial.

In the process of future philologists' professional pedagogical training on the basis of axiological approach, students expand the system of human and professional values that will definitely play a big role in the development of human values [3, p. 38-39].

Axiological approach to education is a philosophical-and-pedagogical strategy, which shows ways of development of professional skills, use of educational resources for development of a personality and offers prospects for improvement of the educational system [1]. 


\section{CONCLUSIONS}

So, we come to the conclusion that the use of axiological approach in professional pedagogical education is caused by the need to train future philologists on the basis of new humanistic principles, aimed at forming professionals who have rich internal culture and wide system of value orientations and can create valuable symbiosis of effective education and moral upbringing on the basis of common values. Among future prospects of the research we see the need to analyze the process of formation of future philologists' professional competence from the point of view of other approaches, including task, personality, activity, cultural, individual-and-creative, acmeological and anthropological approaches.

\section{References}

[1] Artyukhovych Yu. "Teaching values": axiological approach to the problem of education (Bulletin of the North Caucasus State Technical University. Series "Humanities", 2003, 10), 1-10.

[2] Ilyin V. Axiology. Moscow: MGU, 2005.

[3] Konovalova, OV Methods of implementing of axiological approach on the basis of integration of disciplines "Foreign Language" and "Foreign Literature and Culture": a study of the English language: dissertation of Ph.D in Pedagogy. Moscow, 2010.

[4] Passov Ye. System of terms of methods of teaching, or how we speak and write. S.-Pb.: Zlatoust, 2009.

[5] Slastyonin V. Pedagogy. M: School-Press, 2002.

[6] Gershunsky B. Education as the religion of the third millennium: the harmony of knowledge and faith. Moscow: Russian Pedagogical Society, 2001.

[7] Kiryakova A. Axiological orientation of the concept of personality in the world of education (OGU Bulletin, 1999, 1), 13-19.

[8] Ivin A. Philosophy: Encyclopedic Dictionary. M.: Gardariki, 2006.

[9] Isayev I. Theory and practice of formation of professional-and-pedagogical culture of a higher school teacher. Moscow: Academy, 1993. 